\title{
Subject searching in OPAC of a special library: problems and issues
}

\author{
M.S. SRIDHAR \\ Head, Library and Documentation \\ ISRO Satellite Centre \\ Bangalore. India \\ e-mail: sridharmirle@hotmail.com OR sridhar@isac.ernet.in
}

\begin{abstract}
This paper drawing data from a comparative study of use of Online Public Access Catalogue (OPAC) and card catalogue of ISRO Satellite Centre (ISAC) library examines the steady decline in use of subject searching by end-users and the associated problems and issues; presents data to highlights negligible use of Boolean operators and combination searches, variations in descriptors assigned to books of the same class numbers, too many records tagged too broad descriptors, etc.; Concludes that moving from traditional card catalogue to modern OPAC has not made subject searching more attractive and effective.
\end{abstract}

Keywords OPAC; Subject Search

\section{INTRODUCTION}

'Subject approach' to knowledge has been a long and extensive concern of librarianship and is assumed to be the major approach (access method) of users for a very long period. In the card catalogue days, both classified part of the catalogue and subject catalogue (based on assigned standard descriptors) were assumed to help users to have subject access to the resources of a library. Access by classification number is believed to be more common in Europe and India than in US. Unfortunately very few studies have been conducted in those days to see the relative importance of this approach, success or failure of searches and user behavior towards subject access.

Card catalogues had plenty of cross references to help users even if they are not aware of standard descriptors and the same are lacking in OPACs. On the other hand, card catalogues primarily meant for pre-coordinated search where as OPACs enable postcoordinated searches using Boolean operators and other combination searches. Further, OPACs also enable executing vague and free text queries wherever KWIC indexes are provided, which is a great boon to users who are normally unaware of descriptors selected from thesaurus or subject heading list. Despite limitations users do prefer free-text searching. There are also efforts to create intelligent natural-language front ends which use subject headings / thesaurus for searching OPAC.

\section{SOME PAST STUDIES}

Studies on use of OPAC are plenty and there exists good number of reviews of OPAC studies (Larson, 1991; Heldreth, 1985; O`brien, 1994). In a 30 months transaction analysis of patron search on OPAC of Ohio State University, Norden and Lawrence (1981) found that use of subject search commands increased rapidly (Quoted from Hildreth, 1991, p 262-3). Unfortunately OPACs are criticised as being more difficult to use and less 
serviceable than card catalogues and used more for finding known items rather than to seek information or to solve information based problems (Borgman, 1996, p 494). However, there is a significant and consistent decline in controlled vocabulary based subject searching over years in favour of title keyword searching (Larson, 1991). The relative use of subject index in OPAC varied widely from 10 to $62 \%$ in different studies. In the famous CLR project, subject searching was found to constitute the majority (59\%) (Mathews, et. al. 1983). But, Larson found a gradual decline in the use of the subject index as the size of the database increases. The frequency of title keyword searching exceeded that of subject searching over a period. But, as mentioned before, many title keyword searches are for known items.

'Subject access is the most problematic area of online catalogues' (O'brien, 1994). It often leads to either failure or retrieving too many references. Most of OPAC studies have identified the need to tackle the related issues like free text search, field directed search, training users, adjunct thesaurus help, limiting devices with 'filtering' effect, relevance feed back, ranking of retrieved references, etc., to reduce search failures, as most users cannot be expected to put serious/ extra efforts in subject searching. Even computer literacy does not ensure that users will do better subject searches.

OPAC is a 'black box' to users and they know very little about what happens inside the system. For example, trade off between precision and recall is rarely known to end-users. This may also be true of many library professionals who deal with OPAC routinely. OPACs are diverse in features as well as size. Functional layers mediating access of OPAC are user interface, DBMS interface, DBMS, and database (with indexes). Conceptually they can be grouped into (i) those that deal with the users and (ii) those that deal with the storage and retrieval of bibliographic data. Most enhancements to subject searching are through enhancements of the database and DBMS layers. The database layer can be seen as some portion of the contents of card catalog in machine-readable form. The other layers provide procedures to facilitate the process of delivering information to users (Larson, 1991, p 190-191).

Boolean logic appears to be one of the most difficult aspects of information retrieval and is not 'common sense' for most people (Borgman, 1986, p 390). Users tend to perform simple searches using only the basic features. Even scientists and engineers who have expertise in logic for other applications often use 'AND' and 'OR' in their linguistic sense (Borgman, 1986a, 1986b). The combination search or use of Boolean operator can greatly help users to reduce recall and increase precision so as to obtain a browsable size of hits. Users information needs range from highly specific to very general ones. Yet they make only simple searches. Most users search with single term that defeats the purpose of combination searches and Boolean logic.

"... Users rarely ventured beyond a minimal set of system features. The majority of searches were simple, specifying only one field or data type to be searched... [and] advanced search features.... were rarely used..." (Borgman, 1986, p 389-390). Most studies monitoring transactions have reported significant frequencies of input unidentifiable by the system, aborted sessions and searches with no matches. Not only "usage rates are low enough that many online catalog users probably remain permanent novices" (Borgman, 1986, p 390) but also users tend to perform simple searches using only the basic features and did not utilise index terms or headings unless 'forced' to do so (Borgman, 1986, p 389-390). Like use of other services of library and interactions with 
library, use of OPAC is also skewed with a few using a lot and most using it little. Further, most end users search OPAC only occasionally and do not access the system on a regular basis and they tend to learn only enough to do simple searches reasonably quickly and to regard further instruction as unnecessary and more extensive expertise as a burden (Yuan, 1997, p 218). In OPAC use studies, no-match subject searches ranged from $35 \%$ to $57 \%$ (Borgman, 1986, p 389-390). Dickson (1984) found that $37 \%$ of all title searches and $23 \%$ of all author searches resulted in no matches. She determined that $39.5 \%$ of the no-match title searches and $51.3 \%$ of the no-match author searches were for records that existed in the database and not due to user error in searching (Quoted from Borgman, 1986).

Hirst (1999) through a questionnaire survey of users with different levels of IT expertise about use of hypertext interfaces to LIS found that OPAC searches were mainly conducted for specific items and that most were successful. It may be noted that most of specific item searches are other than subject searches. Interestingly novice users tended to achieve higher success rates than expert users.

" Identifying search terms for the subject catalog is hardest of all, since, people often do not recognise that the subject entries are drawn from a controlled list or thesaurus that is separately searchable itself. Instead, they enter the catalog using the free-text keywords they know best, often on a trial and error basis" (Borgman, 1996, p 497). One way to guide end-users is to enable them to choose a subject term from the classification number of the book. There is a great need to link subject headings to classification numbers.

Drabenstott and Weller (1994) summarised the problems of subject access based on the findings of the past studies : (1) one-third of subject queries fail to produce results (ii) large retrievals (high recall) discourage users from scanning the results (iii) few instances of successful matching of query with controlled vocabulary are one-word queries (iv) users are discouraged by subject access and are seeking alternative approaches. They feel that system designs enhancing subject headings, developing menu-based interfaces and extending online catalog functionality to other databases meet the demands of library staff and not necessarily that of users for search functionality. Hence the problems found in the earliest OPACs still continues to exist as far as users are concerned. They have proposed 'search trees' for subject searching after running an experimental online catalog called ASTUTE.

Search failures are usually due to misspelling, lack of knowledge of thesaurus, 'false drops', lack of user understanding of Boolean operators, lack of cross references, lack of online thesaurus and lack of training. There was a significant positive correlation between the failure rate and the percentage of subject searching (Larson, 1991) and a negative correlation between failure rate and time. Longer the processing time/ rate more the chances of user abandoning the search. Subject searches often lead to unusually high recall and create the problem of information overload. The average number of records retrieved are very high (about 77) and users look only few (about 9) (Larsen, 1991). Often, users prefer browsing shelf rather than browsing through subject access. Larson (1991, p20) concludes that " the desire to do topical searching has not diminished, but that the penalties incurred by the user in the process of using the subject index have led to the decline in use". Even CLR survey found that the topical searching is more prevalent among those who are less experienced with the library and its catalogs (Mathews, et. al., 1986). 
O'brien (1994, p223) says that the "...subject indexing of monographs is both superficial and inadequate" as they lack in-depth treatment particularly for composite books and conference volumes as well as lack of TOC, blurbs, etc. Larson (1991) suggests remedies to problems of subject searching which are grouped under (I) the database (ii) the search processing and retrieval algorithms and (iii) the user interface. The database related remedies include expanding records by adding words from TOC, index and blurbs of books, enhancing records with terms from classification schemes and increasing the number of descriptors per book. The second group of remedies include limiting search results by Boolean intersections using additional terms or dates, partial matching and stemming of keywords, relevance ranking of outputs, automatic mapping from input search terms to controlled vocabulary terms through thesaurus look-up, automatic spelling correction or phonetic matching of terms and relevance feed back. The last group of remedies relating to user interface include 'browsability' of existing subject headings using online thesaurus and classification assignments. However, in the context of digital libraries Lesk (2003) questions the very need for traditional subject classification and indexing (which are usually meant for a possible future query) when the actual query itself can be searched on demand in seconds. Multistage searching and display, saving searches, set building, etc. are considered as no more required in the Web and future digital libraries. The new bibliographic model FRBR (The Functional Requirements for

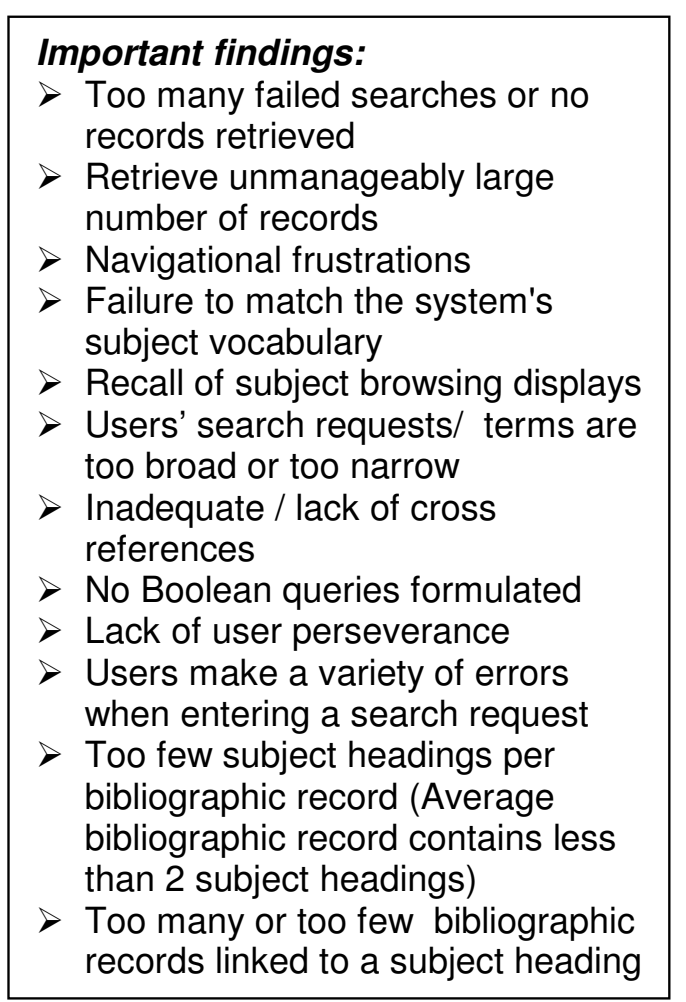
hopes for subject access by way of suggesting retrieval of groups of related documents. This program is suppose to generate sets of records that can be grouped for display as single works irrespective of their manifestations.

In a transaction log analysis of OCLC online catalogs Tolle (1983) worked out correlation coefficients for transaction search patterns and found that the probability of going from 'begin' state to 'browse' is the highest (0.643) and going from one 'error' to another 'error' state is the next highest (0.598). In other words, once an error was made, the next transaction/command was an error in $59.8 \%$ of times. Hardly less than $9 \%$ moved from an error state to ending the session. This speaks of user frustration and waste of lot of efforts of end-users.

The degree of variability of subject searching in an OPAC at a university library revealed that subject searching varied from $22 \%$ to $74 \%$ over the hours of the day, from $17 \%$ to $64 \%$ over the days of the week and from $12 \%$ to $70 \%$ over weeks of the semister (Kaske, 1988a, 1988b). A more recent questionnaire based survey (Oduwole, A A et.al, 2002) of use of OPAC by 286 users at a Nigerian University found that OPAC was used mostly for self search rather than delegated search with author as major (59\%) access point followed by subject $(30.8 \%)$ and large majority were found very satisfied $(75 \%)$ with the OPAC. 
Extensive review of past OPAC use studies is neither feasible nor desirable. However, some of the important findings and suggestions are summarized in the adjacent boxes.

\section{BACKGROUND OF THE STUDY}

An observation-based study of use of card catalogue of ISRO Satellite Centre (ISAC) library carried out during 1985 (Sridhar, 1986) revealed that classified catalogue was not used, report number catalogue (which is like classified catalogue for reports) was negligibly used, author and title catalogues were moderately used and subject catalogue was heavily used. The library was automated during early 80 s and the OPAC was made available on LAN from 1991. A study (Sridhar, 2004) of use of OPAC based on observation, interaction with users and recording by professional staff at the site is done for over 80 hours (equivalent of 10 working days or two working weeks) with due representation for all times of the day and all days of the week during JulyAugust 2002. Unfortunately, the new software does not provide for collecting transaction $\log$ data of OPAC. At the time of study, OPAC (2002) had over 2 lakh records. Surprisingly, when the results of this study was compared with that of earlier (1985) card catalogue study, it was found that the quantum of usage of OPAC is not even as much as what it was in case of card catalogue. The data from this study was extracted to further investigate issues and problems relating to decline in subject searching.

\section{DATA AND DISCUSSION}

The kind of access users prefer while searching OPAC as well as card catalogue are very interesting and probably more revealing for development of search tools and techniques. The above mentioned study (2004) based on critical incident observation has primarily aimed at knowing the approaches of users of ISAC library while searching OPAC. Table I and Figure 1 present the statistics relating to different approaches adopted by users for searching / querying the system. Also juxtaposed in the Table and the corresponding Figure is the data from previous study of use of card catalogue in 1985 (Sridhar, 1986). The data reveals that the title approach is adopted by a maximum of $38.3 \%$ while using OPAC as against a maximum of 54.2\% adopting subject (descriptors) approach in the card catalogue case. It may be noted that additional search features/ approaches like KWIC and combination searches were obviously not found in card catalogue and hence the magnitude of subject search on OPAC can be assumed to be $33 \%$ after adding the KWIC and combination searches. Even then the subject searches have substantially dropped from the time of card catalogue to OPAC days. This is in conformity with the findings of the past studies. As noted earlier, there is generally a small but significant decline in controlled subject searching in favour of keyword (free text) searching (Larson, 1991c). However, even the percentage of searches on author catalogue has dropped from $35.4 \%$ in card catalogue to $26.8 \%$ in OPAC. This also conforms to the findings of Norden, et.al. 
(1981) that title searches were most frequent and the ratio of title to author searches was higher than that in card catalogue. Assuming that specific item searches are mostly nonsubject searches, Hirst (1999) through a questionnaire survey of users with different levels of IT expertise, found that OPAC searches were mainly conducted for specific items and that most were successful. In the present study, hardly $2.5 \%$ of searches are 'combination' searches. These kind of advanced searches are expectedly done by very few end-users and this trend also conforms to the findings of most of earlier studies of OPAC.

\section{Take in Table I and Figure 1}

Concentrating only on major approaches, namely title, author and subject and merging data relating to KWIC searches into that of subject searches, the same data extracted from Table I is presented in Table II. This table together with Figure 1 relating to title, author and subject searches present an interesting comparison of findings of use of OPAC with that of card catalogue. Firstly, searches by title have substantially increased from mere $8.3 \%$ in card catalogue to $38.3 \%$ in OPAC. Secondly, subject searches have dropped substantially from $54.2 \%$ in case of card catalogue to mere $30.7 \%$ (including KWIC searches) in OPAC. However, author approach has marginally dropped (from $35.4 \%$ to $26.8 \%$ ) from card catalogue to OPAC days. On the contrary, subject searching constituted the majority (59\%) in CLR project (Mathews, et.al., 1983).

\section{Take in Table II}

A follow up observation of 51 subject searches made by end-users are depicted in Table III. The data revealed that nearly half of them have met with failure. The rest of little over half of searches $(52.9 \%)$ were considered reasonably successful searches in getting desired results. Out of those met with failure, nearly one-fourth $(23.5 \%)$ have abandoned the search having reached failure. Another one-fourth (23.5\%) changed the search strategy. Out of those who changed search strategy, $13.7 \%$ changed keywords.

\section{Take in Table III}

It has been very clear from the results of the past studies that the majority of end-users face problems with subject searching and one of the major issues is concerned with the selection of appropriate standardized descriptors by end-users. It is also clear that users do not prefer searching by classification numbers and there is no online help regarding thesaurus and/ or classification scheme. There is a need to create link between classification numbers and the corresponding descriptors. Further, too many or too few bibliographic records are linked to a subject heading as well as too few subject headings are assigned per record (average 2) and hence there is a need to review the frequency of assigned subject headings. Table IV depicts an analysis of descriptors in 920 books from 20 sample class numbers at ISRO Satellite Centre library. Surprisingly, the average number of descriptors assigned per book varied from as low as 1.39 in case of Safety related books to a moderate 2.75 in case of Solar Physics/ System related books with overall average a meager 1.89. Further, the SD is also very low. In other words, much against the cry that more descriptors need to be assigned to the books, the collection continues to be indexed with fewer keywords than desired. The sample books had 599 unique keywords assigned 1737 times. The last column of Table IV depicts ratio of number of unique descriptors to number of books in each subject (class no.). As this ratio 
increases the precision of single descriptor search increases. Unfortunately, except few, this ratio is not even one for most of subjects and the highest is just 1.63.

\section{Take in Table IV}

An analysis of frequency of occurrence of descriptors in the entire OPAC revealed further surprises. Fifty seven most frequently occurring descriptors appearing 20452 times in OPAC are listed in Table V. Most of descriptors in Table V are very broad topics and unless they are used in post-coordinated or Boolean searches or in combination with other fields, they will result in too many records and become unmanageable for end-users.

\section{Take in Table $V$}

A frequency table of descriptors used for indexing books is depicted in Table VI. ISAC Library uses NASA Thesaurus for indexing books by way of assigning up-to six postable terms from out of 18,100 postable terms listed in NASA thesaurus (which has totally 41,300 entries). It is clear from the table that only 936 descriptors (postable terms) are assigned to more than ten books in a collection of about 39,000 books. In other words, as many as 13,600 descriptors out of 18100 postable terms (i.e., 75.2\%) in NASA thesaurus remain unused. It is shocking that professional indexers have made least use of specialized thesaurus meant for space science and technology while indexing books in a space science and technology library.

\section{Take in Table VI}

While most frequently used terms (as shown in Table V) cause problems of precision, the unused and least used descriptors (as shown in Table VI) cause problems of recall. As descriptors are drawn from a specialized thesaurus meant for space science and technology, such infrequent (including non use) as well as most frequent use of small set of descriptors appears to be the result of variation in indexing level over time and also from indexer to indexer. The problem may not be uncommon in libraries, but the quality of indexing is a serious concern, if at all subject searching has to be promoted among users. Past research has repeatedly found that failure to match the system's subject vocabulary, recall of subject browsing displays with thesaurus lookup facility and inadequate / lack of cross references as serious drawbacks for subject searching. Obviously many have suggested for allowing use of natural language, providing additional search aids like search trees, pointing users from nonstandard keywords to descriptors, development of ontological and other automatic categorization techniques.

\section{CONCLUSION}

The search process in online catalogues has more or less remained same as in card catalogue with increased access points, varieties of search features but with increased complexity of the process. End-users are not only expected to have technical searching skills but also conceptual and semantic knowledge relating to query in case of subject searching in order to articulate the query. Both indexing quality and under usage of subject access in OPAC cause serious concern about the so called 'subject approach' to knowledge. Inconsistent indexing quality has made the subject searching further difficult and ineffective. In addition to end-user training and other remedies suggested, total new look into interactive searching like drag and drop text from hits, 'more like this' feature, online thesaurus lookup with classification link, partial matching, auto AND search, etc. 
are required. Among many suggestions made to the vendor of software is the provision for indicating the intended use/ application and / or level of book such as beginner, general, specialized / advanced, review, etc., which often helps to improve the precision of the search and utility of the hits in OPAC. Lastly, adding intelligent components like quality addition based on community rating/ use statistics, automatic updation, etc. are necessary.

\section{ACKNOWLEDGEMENT}

\section{REFERENCES}

Alzofon, Sammy R and Van Pulis, Noelle (1984). Patterns of searching and succcess rates in an online public access catalog. College \& Research Libraries. March; 45(2), 110-115

Banks, Julie (2000). Are transactions log useful? A ten-year study. Journal of Southern Academic \& Special Librarianship, February; Vol. 1, No. 3

Borgman, Christine L. (1986). Why are online catalogs hard to use? Lessons learned from information retrieval studies. Journal of the American Society for Information Science, 37(6), 387400.

Borgman, Christine L. (1996). Why are online catalogs still hard to use? Journal of the American Society for Information Science, 47(7), 493-503.

Drone, Jeanette M. (1984), "A use study of the card catalogue in the University of Illinois Music Library", Library resources and technical services, Vol. 28 No.3, July/September, pp. 253.

Ferguson, Douglas et al (1982). The CLR public online catalog study: an overview. Information Technology \& Libraries. June, 1(2),84-97

Gorman, Michael and Jami Hotsinpiller. (1979), "ISBD: Aid or barrier to understanding?", College and research libraries, Vol. 40 No. 6, November, pp. 251.

Gouke, Mary Noel and Pease, Sue (1982). Title searches in an online catalog and a card catalog: a comparative study of patron success in two libraries. Journal of Academic Librarianship. July, 8(3), $137-143$

Hildreth, Charles R.(1985). Online Public Access Catalogs. In: Martha E. Williams (Ed.) Annual Review of Information Science and Technology (ARIST), NY: Knowledge Industrial Inc. Vol. 20, pp. 232-285.

Hirst, S.J.(1998). Hyperlib deliverable 1.2: In-depth survey of OPAC usage. Part of Hyperlib electronic document store, University of Antwerp - University of Loughborough www.lia.ua.ac.be/MAN/P12/root.html

Kaske, Neal K. (1988a). The variability and intensity over time of subject searching in an online public access catalog. Information Technology \& Libraries 7(3),273-287

Kaske, Neal K. (1988b). The comparative study of subject searching in an OPAC among branch libraries of a University Library system. Information Technology \& Libraries 7(4),359-372

Larson, Ray R. (1991). Between Scylla and Charybdis: Subject searching in the online catalog. Advances in Librarianship, edited by Irene P. Godden, San Diego Academic Press, Vol.15, 175-236.

Lesk, Michael (2003). Collecting for a digital library: size does matter. Information Management and Technology 36(4) October-December 2003, 184-187. 
Matthews, Joe (nd). Value of Library Services : A presentation to the Joint Chapter Professional Development Day. www.sla.org/chapter/cpnw/postings/0401Mathews.ppt

Matthews, Joseph R., Gary S. Lawrence and Douglas K. Ferguson (1983). Using online catalogs: A nationwide survey. A report of a study sponsored by the Council on Library Resources. In: Matthews, Joseph R. (Editor) The impact of online catalogs. New York: Neal-Schuman.

McCarthy, Cavan. (1975), "Colonial cataloguing", New Library World, Vol. 76 No.897, March, pp. 55-56. (Quoted from Ken Jones, conflict and change in library organizations: people, power and service, Longdon: Clive Bingley. 1984, pp.29).

Norden, David J. and Lawrence, Gail herndon (1981). Public terminal use in an online catalog: some preliminary results. College \& Research Libraries. July,42(2),308-316.

O’Brien, A. (1994). Online catalogs: Enhancements and developments, in Martha E. Williams (Ed.) Annual review of information science and technology, 29, 219-242. Medford, NJ: Learned Information.

Oduwole, A.A et.al. (2002), "On-line public access catalogue (OPAC) use in Nigerian academic libraries: a case study from the university of agriculture, Abeokuta", Library Herald, Vol. 40 No. 1, March, pp. 20-27.

Sridhar, M.S. (1982), "A study of library visits and in-house use of library documents by Indian space technologists", Journal of Library and Information Science, Vol. 7 No. 2, December, pp. 146-158.

Sridhar, M.S. (1983), "User participation in collection building in a special library: a case study", IASLIC Bulletin, Vol. 28 No. 3, September, pp. 117-122.

Sridhar, M.S. (1985), "A case study of lent-out use of a special library", Library Science with a slant to Documentation, Vol. 22 No. 1, March, pp. 19-34.

Sridhar, M.S. (1986), "Pattern of card catalogue consultation in a special library", IASLIC Bulletin, Vol. 31 No. 1, March, pp. 9-16.

Sridhar, M.S. (1988), "Library-use index and library-interaction index as measures of effectiveness of a special library: a case study", Proceedings of XXXIV All India Library Conference on Library and Information Services: Assessment and Effectiveness, Calcutta: ILA, pp. 449-465.

Sridhar, M.S. (1989), "Information-seeking behaviour of the Indian space technologists", Library Science with a slant to Documentation and Information Studies, Vol. 26 No. 2, June, pp. 127-165.

Sridhar, M. S. (1989), "Patterns of user-visit, movement and length of stay in a special library: a case study." Annals of Library Science and Documentation, Vol. 36 No. 4, pp. 134-138.

Sridhar, M. S. (1994), "Non-users and non-use of libraries", Library Science with a slant to Documentation and Information Studies, Vol. 31 No. 3, September, pp. 115-128.

Sridhar, M. S. (1995a), " Understanding the user - why, what and how?", Library Science with a slant to Documentation and Information Studies, Vol. 32 No. 4, December, pp. 151- 164.

Sridhar, M. S. (1995b), Information behaviour of scientists and engineers, Concept Publishing Company, New Delhi.

Sridhar, M. S. (2002), Library use and user research: with twenty case studies, Concept Publishing Company, New Delhi.

Sridhar, M. S. (2004), OPAC vs. card catalogue : a comparative study of user behaviour the Electronic Library, Vol. 24 No. 2, Mar/ Apr 2004, pp. . (In press). 
Wilson, Patrik. (1983), "The catalog as access mechanism: background and concepts", Library resources and technical services, Vol. 27 No. 1, Jan/Mar, pp. 6-16.

Yuan, W. (1997). End-user searching behavior in information retrieval: a longitudinal study. Journal of the American Society for Information Science, 48(3), 218-234.

TABLES AND FIGURE

\begin{tabular}{|c|c|c|c|c|}
\hline $\begin{array}{c}\text { Table I } \\
\text { Type of search/ access }\end{array}$ & $\begin{array}{l}\text { Access } \\
\text { OPAC }\end{array}$ & $\begin{array}{l}\text { oint/, } \\
\text { 002) }\end{array}$ & $\begin{array}{l}\text { Approach } \\
\text { Card catalo }\end{array}$ & 985) \\
\hline & No. & $\%$ & No. & $\%$ \\
\hline Title & $\overline{150}$ & $38 \overline{3}$ & $\overline{8}$ & $8 . \overline{3}$ \\
\hline Author & 105 & 26.8 & 34 & 35.4 \\
\hline Subject (keyword) & 90 & 23 & 52 & 54.2 \\
\hline Class No./ Report No. & 5 & 1.3 & 2 & 2.1 \\
\hline Place of publication & 1 & 0.2 & NA & NA \\
\hline Publisher & 1 & 0.2 & NA & NA \\
\hline Word in title (KWIC) & 30 & 7.7 & NA & $\mathrm{NA}$ \\
\hline Combination search & 10 & 2.5 & NA & NA \\
\hline $\begin{array}{l}\text { Total } \\
\text { Key: NA, Not applicable }\end{array}$ & 392 & 100 & 96 & 100 \\
\hline
\end{tabular}

FIGURE 1 Access point/ Approach OPAC and card catalogue

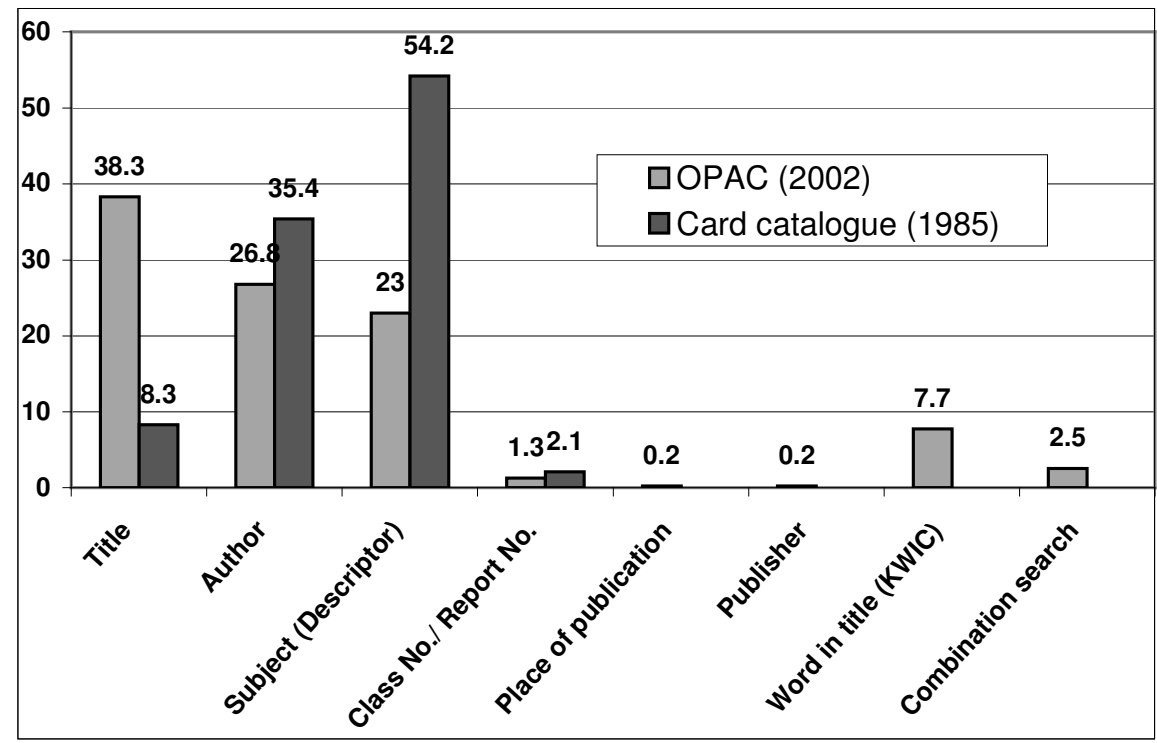

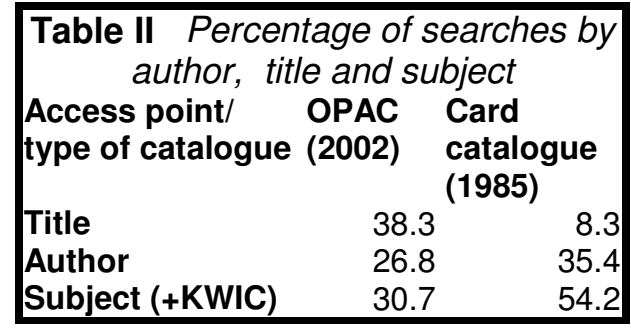

Table III Success or failure of Subject searches

Successes

No. $\%$

$27 \quad 52.9$

Failures:

- Abandoned

$12 \quad 23.5$

- Changed keywords

$7 \quad 13.7$

- Changed search

Sub total

$\underline{5} \quad \underline{9.8}$

$24 \quad 47.1$

Total 


\begin{tabular}{|c|c|c|c|c|c|c|c|c|}
\hline $\begin{array}{l}\text { Sl. } \\
\text { No. }\end{array}$ & Class. No. & able I V Sample class $n$ & $\begin{array}{l}\text { No. of } \\
\text { books }\end{array}$ & $\begin{array}{l}\text { No. of } \\
\text { descriptors }\end{array}$ & rage & escrip & $\begin{array}{l}\text { No. of } \\
\text { unique } \\
\text { descriptors }\end{array}$ & $\begin{array}{l}\text { Ratio of } \\
\text { unique } \\
\text { descriptors } \\
\text { to books }\end{array}$ \\
\hline 1 & 523.9 & The Sun, Solar physics & 24 & 66 & 2.75 & 1.27 & 39 & 1.63 \\
\hline 2 & 528.8 & $\begin{array}{l}\text { Remote sensing } \\
\text { Electromagentism, Electromagnetic } \\
\text { field. Electrodynamics. Maxwell }\end{array}$ & 79 & 156 & 1.97 & 1.21 & 50 & 0.63 \\
\hline 3 & 537.8 & theory & 52 & 86 & 1.65 & 1.26 & 28 & 0.54 \\
\hline 4 & 539.216 .2 & $\begin{array}{l}\text { Films, Thin films } \\
\text { Accidents prevention, Protection }\end{array}$ & 24 & 35 & 1.46 & 1.00 & 14 & 0.58 \\
\hline 5 & 614.8 & safety & 28 & 39 & 1.39 & 0.88 & 21 & 0.75 \\
\hline 6 & 621.3.049.7 & $\begin{array}{l}\text { Printed circuits and the like } \\
\text { Conversion of } A C \text { ito } D C \& \text { vice }\end{array}$ & 10 & 21 & 2.10 & 0.89 & 11 & 1.10 \\
\hline 7 & $\begin{array}{l}621.314 .5 \\
621.38 .049 .771 .1\end{array}$ & 1 versa, convertors, invertors & 17 & 41 & 2.41 & 1.18 & 20 & 1.18 \\
\hline 8 & 4 & Microprocessors & 243 & 409 & 1.68 & 1.10 & 68 & 0.28 \\
\hline 9 & 621.37 .04 & Microelectronics & 32 & 71 & 2.22 & 1.11 & 28 & 0.88 \\
\hline 10 & 621.381 .542 & $\begin{array}{l}\text { Image analysis } \\
\text { Barrier layer photocells, Photovoltaic } \\
\text { cells, Photodiodes, }\end{array}$ & 30 & 71 & 2.37 & 1.57 & 38 & 1.27 \\
\hline 11 & 621.383 .5 & Phototranssistors & 15 & 23 & 1.53 & 0.65 & 6 & 0.40 \\
\hline 12 & 621.396 .67 & Aerial systems & 79 & 150 & 1.90 & 1.86 & 55 & 0.70 \\
\hline 13 & 621.390 .96 & Radar & 58 & 107 & 1.84 & 1.92 & 55 & 0.95 \\
\hline 14 & 629.7.036.5 & Rocket propulsion & 8 & 18 & 2.25 & 1.44 & 13 & 1.63 \\
\hline 15 & 629.73 & Aeronautical engineering & 25 & 48 & 1.92 & 1.27 & 28 & 1.12 \\
\hline 16 & 629.785 & Space probes & 21 & 52 & 2.48 & 1.01 & 21 & 1.00 \\
\hline 17 & 658.562 & Quality control & 65 & 110 & 1.69 & 0.58 & 22 & 0.34 \\
\hline 18 & 681.3 .02 & $\begin{array}{l}\text { Design, construction layout of DP } \\
\text { systems }\end{array}$ & 77 & 177 & 2.30 & 1.01 & 62 & 0.81 \\
\hline 19 & 681.3.06vhd & VHDL (computers) & 15 & 25 & 1.67 & 0.36 & 9 & 0.60 \\
\hline 20 & 681.351 & Computer networks & 18 & 32 & 1.78 & 0.40 & 11 & 0.61 \\
\hline Tot & & & 920 & 1737 & 1.89 & & 599 & 0.65 \\
\hline
\end{tabular}




\begin{tabular}{|c|c|c|}
\hline \multicolumn{3}{|c|}{$\begin{array}{l}\text { TABLE V } \\
\text { books }\end{array}$} \\
\hline Rank & Descriptor & No. of Books \\
\hline 1 & Computer programming & 1127 \\
\hline 2 & Computer networks & 748 \\
\hline 3 & Signal processing & 745 \\
\hline 4 & Software engineering & 610 \\
\hline 5 & Integrated circuits & 577 \\
\hline 6 & Programming languages & 534 \\
\hline 7 & Control theory & 520 \\
\hline 8 & Neural nets & 515 \\
\hline 9 & Artificial Intelligence & 510 \\
\hline 10 & Communication networks & 470 \\
\hline 11 & Aerospace Engineering & 468 \\
\hline 12 & Computers & 457 \\
\hline 13 & Micro processors & 433 \\
\hline 14 & Remote sensing & 426 \\
\hline 15 & Data processing & 418 \\
\hline 15 & Image processing & 418 \\
\hline 17 & Robotics & 404 \\
\hline 17 & Telecommunication & 404 \\
\hline 19 & Data base management systems & 368 \\
\hline 19 & Dictionaries & 368 \\
\hline 20 & Indexes (Documentation) & 349 \\
\hline 21 & Computer aided design & 343 \\
\hline 22 & Astronomy & 341 \\
\hline 23 & India & 340 \\
\hline 24 & Circuits & 329 \\
\hline 24 & Electrical engineering & 329 \\
\hline 25 & Very large scale integration & 328 \\
\hline 26 & Communication & 324 \\
\hline 26 & Micro computer & 309 \\
\hline 27 & Computer programs & 303 \\
\hline 28 & Multimedia & 299 \\
\hline 29 & Management & 285 \\
\hline 30 & Antennas & 281 \\
\hline 31 & Libraries & 279 \\
\hline 31 & Wireless communication & 279 \\
\hline 33 & Computer graphics & 271 \\
\hline 34 & Industries & 266 \\
\hline 35 & Quality control & 264 \\
\hline 36 & Expert systems & 263 \\
\hline 36 & Operating systems (computers) & 260 \\
\hline 37 & Architecture (computers) & 259 \\
\hline 38 & Internets & 257 \\
\hline 39 & Heat transfer & 248 \\
\hline 40 & Bibliographies & 247 \\
\hline 41 & Manufacturing & 246 \\
\hline 42 & $\mathrm{C}$ (Programming Language) & 245 \\
\hline 43 & Robots & 238 \\
\hline 44 & Medical science & 234 \\
\hline 45 & Algorithms & 220 \\
\hline 45 & Electronic equipment & 220 \\
\hline 47 & Lasers & 217 \\
\hline 47 & Reliability & 217 \\
\hline 48 & $\mathrm{C}++$ (Programming Language) & 213 \\
\hline 49 & Databases & 207 \\
\hline 49 & Micro waves & 211 \\
\hline 50 & Propulsion & 206 \\
\hline$\underline{51}$ & Object-oriented programming & 205 \\
\hline & Total (57 Descriptors) & 20452 \\
\hline
\end{tabular}

\begin{tabular}{|c|c|}
\hline \multicolumn{2}{|c|}{$\begin{array}{l}\text { TABLE VI Descriptors with least } \\
\text { number of records/ books (Frequency } \\
\text { distribution of least assigned } \\
\text { descriptors) }\end{array}$} \\
\hline No. of descriptors & No. of Books (Records) \\
\hline 1,539 & 1 \\
\hline 658 & 2 \\
\hline 367 & 3 \\
\hline 281 & 4 \\
\hline 196 & 5 \\
\hline 159 & 6 \\
\hline 122 & 7 \\
\hline 93 & 8 \\
\hline 70 & 9 \\
\hline 75 & 10 \\
\hline \multicolumn{2}{|l|}{ Sub-total 3,560} \\
\hline 936 & $>10$ \\
\hline 13,004 & (unused) $\quad 0$ \\
\hline 18,100 & \\
\hline
\end{tabular}




\begin{abstract}
About the Author
Dr. M.S.Sridhar is a post graduate in mathematics and business management and a doctorate in library and information science. He is in the profession for last 35 years. Since 1978 he is heading the Library and Documentation Division of ISRO Satellite Centre, Bangalore. Earlier he has worked in the libraries of National Aeronautical Laboratory (Bangalore), Indian Institute of Management (Bangalore) and University of Mysore. Dr. Sridhar has published four books ('User research: a review of information-behaviour studies in science and technology', 'Problems of collection development in special libraries', 'Information behaviour of scientists and engineers' and 'Use and user research with twenty case studies') and 74 research papers, written 19 course material for BLIS and MLIS, presented over 22 papers in conferences and seminars, and contributed 5 chapters to books.
\end{abstract}

